\title{
O PROJETO MINERVA E O REGIME MILITAR NO BRASIL: CONSIDERAÇÕES SOBRE A CENSURA
}

\author{
THE MINERVA PROJECT AND THE MILITARY REGIME \\ IN BRAZIL: CENSOR CONSIDERATIONS \\ EL PROYECTO MINERVA Y EL RÉGIMEN MILITAR \\ EN BRASIL: CONSIDERACIONES DEL CENSOR \\ Giovani GonÇALVES Pinheiro ${ }^{\mathrm{I}}$ \\ APARECIDA FAVORETO ${ }^{\mathrm{I}}$ \\ 'Universidade Estadual do Oeste do Paraná (UNIOESTE), Cascavel/PR - Brasil
}

\begin{abstract}
Resumo Este artigo surgiu do interesse em compreender os fundamentos de um pedido de busca ao posto do Projeto Minerva $(1970$ - 1991) que suspeitava de uma infiltração de ideias comunistas em sua dependência. Para tanto, buscou-se saber o que foi o Projeto Minerva em seu contexto histórico-social, atentando-se para o embate político e como ocorria a censura política no período. Por intermédio de pesquisa bibliográfica, documental e de entrevistas, constatou-se que o Projeto Minerva se constituiu no processo de desenvolvimento tecnológico das comunicações e buscou corresponder à demanda da produção por educação no período. No que se refere à censura, destaca-se que, de forma progressiva, ela foi se tornando mais austera e um complexo aparato de investigação e de punição foi criado. Porém, mais do que restrições à liberdade e ao controle na circulação da informação, juntamente com a educação, a censura foi utilizada ideologicamente pela ação propagandista do Estado. Neste sentido, a suspeita acima mencionada diz muito sobre a mistificação política instaurada na época, na qual os militares se apoiavam para legitimar e manter sua hegemonia política.
\end{abstract}

Palavras-chave: Projeto Minerva, Regime Militar, Censura Política

ABSTRACT This article arose from the interest in understanding the reason of a search request to investigate a suspecting communist infiltration in one of the Minerva Project's post (1970 - 1991). We sought to know the Minerva Project historical-social context, paying attention to the political clash and how the political censorship took place in the period. 
Through bibliographic, documental, and interview research, it was found that the Minerva Project was constituted in the process of technological development of communications and sought to correspond to the demand for education in the period. In relation to censorship, it is noteworthy that it progressively became more austere and a complex apparatus of investigation and punishment was created. However, more than restrictions to freedom and control in the circulation of information, along with education, the propagandist action of the State ideologically used censorship. In this sense, the suspicion says a lot about the mystification policy instated at the time, on which the military relied to legitimize and maintain its political hegemony.

\section{Keywords: Minerva Project, Military Regime, Political Censorship}

RESUMEN Este artículo surge del interés por comprender los fundamentos de una solicitud de búsqueda del puesto del Proyecto Minerva (1970 - 1991) que sospechaba una infiltración de ideas comunistas en su dependencia. Por ello, se buscó conocer qué era el Proyecto Minerva en su contexto histórico-social, prestando atención al choque político y cómo se produjo la censura política en el período. A través de investigaciones bibliográficas, documentales y entrevistas, se encontró que el Proyecto Minerva se constituyó en el proceso de desarrollo tecnológico de las comunicaciones y buscó corresponder a la demanda de producción educativa en el período. En cuanto a la censura, cabe señalar que, progresivamente, se hizo más estricta y se creó un complejo aparato de investigación y sanción. Sin embargo, más que restricciones a la libertad y control en la circulación de la información, junto con la educación, la censura fue utilizada ideológicamente por la acción propagandista del Estado. En este sentido, la sospecha antes mencionada dice mucho sobre la mistificación política establecida en ese momento, en la que los militares se apoyaron para legitimar y mantener su hegemonía política.

Palabras-clave: Proyecto Minerva, Régimen Militar, Censura Política.

\section{INTRODUÇÃo}

Esse artigo, em uma perspectiva histórica, pontua algumas reflexões sobre o Projeto Minerva $(1970 \text { - 1991) })^{1}$, o qual foi constituído durante o Regime Civil-Militar brasileiro (1964 - 1985). Neste estudo, ao passo em que se apresenta o que foi o Projeto e pontua alguns elementos históricos que possam ter influenciado sua configuração e forma de produção, também investiga como ocorreu o embate político e a censura no seu interior. A partir disso, apontam-se algumas considerações sobre o significado social da censura política e como o Estado Civil-Militar se utilizou da educação e da censura na constituição da sua hegemonia política.

O interesse originou-se do resgate de um documento de 17 de novembro de 1971, do Centro de Informações da Polícia Federal, protocolado no estado do Paraná e disponível no Arquivo Público do Paraná, em que consta um pedido de busca (608/71) ao posto do

O Projeto Minerva, criado em 1970 pelo Ministério da Educação e Cultura do Regime Militar, tratava-se de um Curso Supletivo, de Educação a Distância (EaD), montado junto ao Rádio MEC. Inicialmente, voltou-se para o $1^{\circ}$ grau e depois também para o $2^{\circ}$ grau. Com o avanço da tecnologia, a qual trouxe o desenvolvimento da televisão e, posteriormente, da Internet, o rádio foi perdendo espaço como $\mathrm{EaD}$, até que em 1989 saiu do ar, encerrando definitivamente suas atividades em 1991. 
Projeto Minerva. No caso, a suspeita era que havia "infiltração de comunistas no programa da rádio MEC, Projeto Minerva da Educação"2.

Sendo tal suspeita um dado inédito na história da educação brasileira ${ }^{3}$, buscou-se averiguar seus fundamentos. Para isto, priorizou-se o uso de fontes primárias, ou seja, publicações de documentos oficiais expedidos pela União. No entanto, diante da dificuldade de acessar todas as fontes ${ }^{4}$, utilizou-se de alguns documentos citados por outros pesquisadores, divulgados em forma de teses, dissertações, livros e artigos científicos. Também aproveitou de alguns relatos de membros que contribuíram com o desenvolvimento do Projeto Minerva, os quais foram colhidos e disponibilizados pela Sociedade dos Amigos da Rádio Ministério da Educação e Cultura (SOARMEC), bem como realizou-se uma entrevista com uma das coordenadoras do Projeto Minerva, Marlene Blois (2015) ${ }^{5}$, na qual buscou-se averiguar sua experiência com a censura no interior do programa e como ela compreendia a suspeita mencionada acima.

Importa ainda destacar que o objetivo do artigo, mais do que transcrever o que era o Projeto Minerva e/ou responder se houve ou não a infiltração de ideias comunistas, foi compreender o significado histórico-social da problemática. Nesse propósito, buscou-se apresentar o Projeto Minerva e a censura, não como elementos isolados, mas situados em um processo histórico de desenvolvimento tecnológico das comunicações, de reorganização da produção industrial capitalista e de embates políticos. Assim, procurou-se estabelecer relações entre as informações e o contexto, de modo a verificar como os aparelhos ideológicos da educação e da censura foram utilizados na busca de legitimar e manter a hegemonia política civil-militar. Para isto, tal pesquisa apoiou-se em alguns intérpretes da história sócio-política brasileira e da história da educação, dentre os quais foram priorizados os teóricos que estabelecem relações entre as medidas educacionais, as lutas ideológicas e as necessidades da produção capitalista na época. Neste aspecto, os dados coletados sobre o Projeto Minerva e a censura foram vistos e analisados como produtos históricos.

\section{O Projeto Minerva e a conjuntura histórica}

O Projeto Minerva se constituiu na forma de Educação a Distância e foi voltado para a formação de jovens e adultos ${ }^{6}$. Sua implantação e forma de incremento se relacionaram ao

2 Ministério da Justiça (1971). Disponível em: https://www.documentosrevelados.com.br.

3 Geralmente, a historiografia brasileira aponta que o sistema de ensino na época seguia o direcionamento político e ideológico da cúpula militar e possuía um severo controle ideológico em prol dos interesses do Regime e do capitalismo. Sobre, consultar: Germano (1994), Cunha (1978), Gaspari, (2002).

4 Sobre os documentos da Rádio MEC e do Projeto Minerva, informamos que eles permaneceram arquivados até 2013, nas dependências da SOARMEC. Atualmente, todo o material está aos cuidados da EBC (Empresa Brasil de Comunicação), a qual informou que está em fase de digitalização, podendo disponibilizá-los futuramente, porém, sem data prevista. Sendo assim, até a fase final desta pesquisa (outubro, 2017), o material não estava disponível ao público.

5 Marlene Blois foi professora e coordenadora do Projeto Minerva no Rio de Janeiro, entre 1973 a 1980. A referida entrevista foi realizada em junho de 2015, no Rio de Janeiro, por um dos autores deste artigo, a qual encontra-se citada em Pinheiro (2016).

6 No Brasil, até os anos 1970, muitos projetos educacionais foram criados para a formação de adultos, entre os quais citam-se a Universidade do Ar do SESC e SENAI, em 1947; o Projeto Sirena, em 1957; o Movimento de Educação de Base (MEB), em 1961; o Mobral, em 1967. 
desenvolvimento das tecnologias da comunicação e com as necessidades da produção e a organização política. Na época (final da década de 1960), o Ministério da Educação percebeu, no rádio, uma alternativa viável para implantar um projeto de formação escolar de caráter nacional, pois as ondas, como se dizia na época, encurtavam distâncias. Assim, em termos geográficos, o rádio contribuía para transmitir conteúdo educacional para os lugares mais distantes e isolados, almejando atingir todo o território nacional. Nesse mesmo sentido, também aspirou chegar a um maior número de pessoas, sem elevar, em muito, o orçamento da União.

O Projeto Minerva, em parte, se funde com a história do rádio. Aliás, a Rádio MEC teve sua origem na Rádio Sociedade do Rio do Janeiro, fundada em 1922. Sobre o assunto, Roquette-Pinto ${ }^{7}$ (2002-2003), em suas memórias, afirma que na fundação da Rádio, já pressentia que o rádio seria um veículo para ampliar o acesso à educação para os locais mais distantes do país. Em 1936, com problemas financeiros, a Rádio foi doada ao Ministério da Educação (PINTO e GARNICA, 2014).

Incorporando o rádio como instrumento a serviço da educação, o Projeto Minerva lançou, entre seus objetivos, preparar a população para novos desafios produtivos, garantir o ensino e a difusão cultural, bem como elevar os índices escolares no Brasil. Igualmente, os membros do Conselho Nacional de Educação da época, na análise do Projeto, afirmaram que "programas do tipo Projeto Minerva representam algo de essencial à formação de cidadãos mais capazes, como fator de desenvolvimento econômico e social" (VEJA, 1973, $\mathrm{n}^{\circ} 241$, p. 54 apud GONZALEZ e SARAIVA, 2017, p. 11).

Entretanto, em que pesem as perspectivas de aumentar o número de escolarizados e atender às demandas produtivas e sociais, a cúpula militar também cuidou para que os ideais educacionais voltassem, exclusivamente, aos princípios político-ideológico do Regime. Assim, antes mesmo de implantar o Projeto, houve a extinção de algumas ações educativas que o comando julgava serem adversas aos seus ideais. Um exemplo disso foi a Campanha Nacional de Alfabetização que se baseava no Método Paulo Freire ${ }^{8}$, a qual foi extinta em 1964 e seu idealizador foi apontado como subversivo e inimigo do povo brasileiro, sendo por isto, encarcerado e exilado.

Sobre as perspectivas do Projeto Minerva, ou seja, para ampliar a formação, preparar a população para novos desafios produtivos e cuidar dos princípios político-ideológico da educação escolar, destaca-se que elas se constituíram em meio a um conjunto de outras medidas, as quais marcaram o contexto. Neste sentido, tão logo a cúpula militar tomou o poder executivo, de forma progressiva, diversas mudanças políticas, econômicas, discursivas e administrativas foram realizadas para justificar e manter o poder.

No caso, transferindo a culpa para a herança política, econômica e social deixada pelo governo de Goulart, reformas legislativas foram defendidas como necessárias para manter a "ordem" e o "progresso". Desse modo, a Lei foi adequada às necessidades dos interesses do poder político e econômico. Assim, para além dos sucessivos Decretos e Atos

Edgar Roquette-Pinto fundou, a partir de uma associação, a primeira rádio do Brasil, a Rádio Sociedade do Rio de Janeiro em 1922

8 Paulo Freire (1921 - 1997) ficou conhecido pela pedagogia utilizada na alfabetização de adultos, a qual, em 1961, na coordenação de uma equipe em Recife, alfabetizou 300 cortadores de cana em 45 dias. Foi autor de diversos livros, traduzidos em diversos idiomas, nos quais defendeu a alfabetização com consciência crítica e libertadora. Foi recebedor de muitos prêmios e homenagens nacionais e internacionais. 
Institucionais, em 1967, foi promulgada a nova Constituição. De forma gradual, houve a concentração do poder no governo militar, na medida em que se retiraram alguns direitos e limitou-se a representação popular na política9 .

Inúmeras medidas econômicas foram implementadas em conjunto com as reformas políticas no sentido de buscar o crescimento do capita ${ }^{10}$, buscando atender aos interesses da aliança entre as forças empresariais e os militares defensores da Doutrina de Segurança Nacional (ALVES, 1984). De tal modo, os militares investiram na criação de empresas estatais e buscaram atrair o capital internacional, seja na forma de financiamento ou na implantação de empresas multinacionais, entretanto, se houve crescimento da indústria pesada e da mecanização do campo, este se constituiu com base no endividamento externo, em uma política de achatamento salarial e muita repressão, inclusive com mão-de-ferro sobre as organizações dos trabalhadores. Assim, na segunda metade da década de 1980, o Brasil passou a ocupar o $8^{\circ}$ lugar na economia mundial. Entretanto, segundo Chasin (1986), o poder de compra da população passou a ocupar a $54^{\mathrm{a}}$ posição e metade da renda nacional ficava com $1 \%$ da população mais rica.

Em termos educacionais, na década de 1970, o Brasil continuava a apresentar dificuldades, pois, o número de analfabetos adultos ${ }^{11}$ continuava elevado, principalmente na área rural. No processo, todos os níveis escolares passaram por reformas, iniciando com a reforma do Ensino Superior em 1968 e da Educação Básica ( $1^{\circ}$ e $2^{\circ}$ graus) em $1971 . .^{12}$ Influenciados pela Teoria do Capital Humano ${ }^{13}$, os militares buscaram ampliar a oferta de escolaridade e também qualificar a mão-de-obra. Assim, pela Lei 5692/71, ampliou-se a obrigatoriedade do ensino dos 7 aos 14 anos ( $1^{\circ}$ grau) e o $2^{\circ}$ grau assume o caráter de profissionalização obrigatória ${ }^{14}$. A intenção era criar as condições culturais para avançar no projeto desenvolvimentista, bem como aproximar-se das aspirações populares e legitimar o poder dos militares.

Sendo assim, o Grupo de Trabalho das Reformas do Ensino ${ }^{15}$, em seu Relatório, ao se referir às Reformas do Ensino de $1^{\circ} \mathrm{e}$ de $2^{\circ}$ Graus (1971, p. 133), especificou que elas eram socialmente necessárias e poderiam contribuir com o "desenvolvimento socioeconômico".

9 Sobre a tomada de poder, os documentos oficiais do Governo Militar a descrevem como "revolução". Entretanto, a maioria dos historiadores brasileiros, podendo citar: Gaspari (2002) destaca ser um "golpe", pois implicou a interrupção do processo democrático, inclusive com o fechamento do Congresso Nacional, remoção do seu poder fiscalizador, demissões sumárias, cassação de mandatos, suspensão de direitos políticos, impedimento de alguns exercerem sua profissão, além da instauração da censura prévia e perca da liberdade de expressão.

10 Na época, Delfim Netto, então Ministro da Fazenda de Costa e Silva (1967-1969) e de Médici (1969-1973), para justificar as perdas salariais, muitas vezes repetiu que primeiramente deveria "fazer o bolo crescer, para depois dividi-lo".

11 Na década de 1970, o índice de analfabetos adultos era de 33,7\% (IBGE, 2007).

$12 \mathrm{O} 1^{\circ}$ grau agrupou o primário e o ginasial, abarcando da $1^{\circ}$ à $8^{\circ}$ série do Ensino Fundamental. $\mathrm{O} 2^{\circ}$ grau absorveu o colegial, conhecido hoje como Ensino Médio.

13 Baseando-se em Schultz, acreditava-se que, pela educação, em específico, pela qualificação da força de trabalho, poder-se-ia acelerar o desenvolvimento socioeconômico.

14 O modelo de ensino tecnicista passa a ser indicado pelo governo, pois, por valorizar o uso da técnica como treino disciplinar da racionalidade, o considerava mais adequado às novas tecnologias, mais rápido e eficaz no ensino. Também o considerava ser um ensino livre de ideologia (GERMANO, 1994).

15 Em 1970, pelo Decreto $n^{\circ}$. 66.600, criou o Grupo de Trabalho das Reformas do Ensino de $1^{\circ}$ e de $2^{\circ}$ Graus, o qual, já em 1971, teve seu trabalho aprovado. Sobre, consultar: Germano (1994) e Favoreto, Figueiredo e Deitos (2019). 
Ainda argumentou que elas poderiam inserir amplos "segmentos da população" à "força de trabalho" e ao "consumo", os quais, anteriormente, estavam "marginalizados". Na mesma linha, o Grupo afirmou que "com a evolução dos conhecimentos", "novas técnicas de produção e formas de vida" seriam necessárias, de modo que a "tradicional educação primária como preparo mínimo do homem comum” tornava-se insuficiente.

No que se refere ao processo de planejamento e execução do Projeto Minerva, é importante registrar que ele envolveu um complexo de ações interligadas, além de um amplo aparelho burocrático, tecnológico e pessoal. Sua transmissão foi autorizada por uma portaria interministerial $n^{\circ}$ 408/70 do Conselho Nacional de Telecomunicações, que tornava obrigatória a transmissão, de forma unificada das $20 \mathrm{~h}$ às $20 \mathrm{~h} 30$, da programação educativa por todas as emissoras de rádio (BRASIL, 1970).

A programação era organizada a partir de uma equipe central no Rio de Janeiro, nas dependências da Rádio MEC. Nesse local, eram realizadas as reuniões para decidir o conteúdo a ser transmitido, via satélite ou por meio de retransmissoras, para todo o país. Também ali, decidiam-se sobre o material didático (radiofônico e fascículos) a ser utilizado nas aulas.

No seu processo de atuação, o Projeto Minerva tanto produziu o próprio material como utilizou o conteúdo das Fundações Roberto Marinho e Padre Anchieta. Na produção do seu material, um especialista de cada área (matemática, língua portuguesa entre outros) decidia e formulava os tópicos. Logo em seguida, o material era transformado em um roteiro de rádio, com todas as indicações sonoras para a parte técnica e para os locutores que participavam da gravação. Depois de pronto, novamente, o roteiro era supervisionado e, se necessário, refeito.

No estúdio, as gravações eram realizadas por locutores profissionais e não por professores, além de músicos e atores. $\mathrm{Na}$ exposição dos assuntos, envolvendo duas ou três pessoas, explanavam-se os conceitos e uso de um assunto. Quando os programas ficavam prontos, eram transmitidos após a Voz do Brasil ou enviados em fitas magnéticas para retransmissoras em outros estados. Os conteúdos trabalhados nas aulas radiofônicas eram seguidos por fascículos, os quais eram enviados aos radiopostos ou vendidos separadamente em bancas de revistas do país.

Os radiopostos funcionavam em salas comunitárias, escolas, salões de igreja, dependências militares ou qualquer outro lugar no qual os estudantes matriculados ouviam meia hora de programa pelo rádio, acompanhando pelo fascículo e solucionavam exercícios com a supervisão de um monitor. As aulas também poderiam ser acompanhadas por ouvintes que não estavam matriculados. Assim, os ouvintes interessados poderiam seguir o conteúdo por meio dos fascículos vendidos em bancas de revistas.

Os fascículos tinham seus conteúdos divididos em áreas do conhecimento e subdivididos em assuntos e, em uma sequência do mais simples para o mais complexo, eram expostos conceitos, dados e fatos. Também traziam exercícios que deveriam ser resolvidos pelos alunos ouvintes nos radiopostos ou em casa. Os formuladores do material, amparados na teoria da neutralidade científica e na defesa de um aprendizado rápido e técnico, priorizaram o pragmatismo, bem como a descrição do conteúdo. Segundo Pinto e Garnica (2014), no processo de aprendizado, o aluno, auxiliado pelo monitor, de forma individualizada, reproduzia os conceitos e os exercícios para treinar sua memória para o uso das técnicas e abstrações. 
Com base em Pinto e Garnica (2014), é possível destacar também que o ensino das ciências exatas, geralmente, partia-se de um problema previamente elaborado; apresentavam-se os conceitos e os passos a serem seguidos na solução do problema. Os alunos, seguindo o modelo padrão, deveriam resolver os exercícios, de modo a chegar ao resultado final.

No que se refere aos conhecimentos sociais, eram organizados na forma de informações, priorizando fatos e dados. Tinham entre as finalidades desenvolver o sentimento nacional, o respeito à ordem e o amor ao trabalhado. Dessa forma, juntamente com a disciplina de Estudos Sociais, criou-se a de Educação Moral e Cívica, nas quais eram repassados valores éticos e morais atrelados ao sentimento nacional e de cidadão responsável e ordeiro. Trazendo informações sobre os feitos dos "heróis" brasileiros, das riquezas nacionais e a importância do governo na manutenção do progresso e da defesa nacional, buscava justificar e preservar a ordem nacional desenvolvimentista, enquanto intencionava-se desautorizar e/ou aniquilar qualquer senso crítico.

Os materiais didáticos, numa linguagem simples e clara, também buscavam divulgar o sentimento ufanista do "Brasil Grande" e da propaganda dos feitos militares. Eles eram produzidos para atingir todo o território nacional. Portanto, houve pouco espaço para adaptação às necessidades específicas de cada região e/ou aluno. Seguindo as aulas radiofônicas e os fascículos, os monitores não tinham autonomia no desenvolvimento da aula. Sobre esta dinâmica, Blois (s/d) em entrevista aos "Amigos Ouvintes" da SOARMEC descreve:

A dinâmica era a seguinte: o aluno chegava às sete e meia, lia o conteúdo da
aula, ele sabia qual era a aula, tinha o mapa de que aula ia ouvir; das 8 às 8:30,
ele ouvia a aula, depois ficava para trabalhar os conteúdos e os exercícios que
estavam no fascículo. Nós estávamos garantindo qualidade da informação, por-
que nós não tínhamos professores formados no Brasil inteiro em número sufi-
ciente. Muitos dos monitores eram os próprios alunos, que se revezavam. Cada
dia era um que virava monitor - às vezes não tinha nenhuma pessoa que tivesse
o antigo primeiro grau completo, que pudesse assumir a monitoria.

Blois $(\mathrm{s} / \mathrm{d})$, nessa mesma entrevista, ainda narra que o pagamento e o contrato dos monitores ficavam a cargo das Secretarias de Educação ou das prefeituras, como forma de contrapartida. Referindo-se aos Monitores, Pinto e Garnica (2014, p. 160) apontam que

o monitor era, normalmente, algum professor ou pessoa com maior formação
na localidade em que os radiopostos eram instalados. Sua função era acompa-
nhar os alunos nas salas de aulas e atividades a serem desenvolvidas. Em nosso
estudo podemos destacar o papel significativo dos monitores no Projeto. Em
algumas localidades havia monitores que utilizavam os materiais do Projeto
para elaborar e ministrar aulas para os jovens e adultos por ele atendidos (atuan-
do, portanto, como professor dos alunos); há casos em que, pela quantidade de
pessoas não alfabetizadas que procuravam os radiopostos, o monitor utilizava
aquele espaço e todo o material do Projeto, fascículos e radioaula, para alfabe-
tizar as pessoas da comunidade.

Segundo Blois (2015), os professores do Projeto eram bem pagos, porém, o mesmo não se poderia dizer dos monitores, ou seja, aqueles que tinham contato direto com os 
alunos, a remuneração era baixa. De forma semelhante, o Instituto de Pesquisa Econômica Aplicada (IPEA), ao relatar sobre o Projeto Minerva, escreve:

\begin{abstract}
Houve, em geral, treinamento para os monitores dos radiopostos e para os supervisores e coordenadores municipais. Mas, a rotatividade deste pessoal, em alguns municípios, dificultou a aplicação das experiências anteriores. Este revezamento é, parcialmente, explicado pelos reduzidos salários oferecidos (IPEA, 1976, p. 153).
\end{abstract}

Cunha (1978) também aponta o baixíssimo salário dos monitores e complementa que o trabalho nos postos era marcado por improvisações, isto, tanto no sentido de que os monitores não tinham qualificação para a função, como também diante das dificuldades culturais dos alunos, a aprendizagem era menos aprofundada. Semelhante a Cunha, Aggarwal (2007); Pinto e Garnica (2014) também apontam que o Projeto apresentava muitos problemas. Neste sentido, citam a ineficiência do rádio como meio de ensino; a falta de entrosamento entre as diversas Secretarias de Educação; a baixíssima remuneração dos monitores, bem como a forma precária que eram contratados e a pouca qualificação exigida na execução do cargo. Neste sentido, Pimentel (2004, p. 88) ainda acrescenta que não havia a "adequação dos conteúdos programáticos aos grupos sociais a serem atingidos e as formas de recepção utilizadas".

No caso, se por um lado, o projeto buscava atender aqueles que estavam excluídos dos bancos escolares, por outro, ao economizar investimento na qualificação e contratação dos monitores/professores nos postos, as dificuldades se agigantavam, repercutindo em um alto índice de reprovação e de desistência. ${ }^{16}$

\title{
Projeto Minerva e a Censura
}

No que se refere à censura no interior do Projeto Minerva, semelhante ao que acontecia em outros órgãos de produção cultural, a figura do censor estava presente. Ele fiscalizava a produção das aulas e propunha cortes e alterações no conteúdo, isto, tanto no que se refere aos textos das cartilhas quanto dos programas radiofônicos transmitidos e/ou enviados em fitas para as retransmissoras. Em termos gerais, a censura tinha como propósito cortar os conteúdos indesejados, principalmente, os que pudessem incitar ideias destoantes ao do Regime Militar, bem como explicitar os bons feitos do Estado Civil-Militar. Neste sentido, pelo fato da produção das radioaulas ser centralizada nas dependências da Rádio MEC, o trabalho do censor na fiscalização e o controle do conteúdo escolar tornavam-se mais fáceis e eficientes.

Renato Rocha (s/d), um dos redatores do Projeto, em entrevista aos "Amigos Ouvintes" da Sociedade dos Amigos da Rádio MEC (SOARMEC), comenta:

Eu cheguei a pegar o tempo em que havia um censor na rádio. Ele era meio ressabiado, pois sabia como era visto por nós. Mas era pacífico. Censura, mesmo, foi

\footnotetext{
16 Sobre os altos índices de reprovação e de desistência, Lustosa (2014) comenta que contribuíram para que os já excluídos do sistema regular de educação se sentissem culpados por seus fracassos.
} 
antes, com o Eremildo Viana, na época dos milicos. É tristemente famosa a gestão dele, com episódios inacreditáveis como o dos scripts da Edna Savaget - sobre poetas russos - que ele queimou no chão da sala dos produtores. Era um tempo em que não se podia tocar músicas de autores russos. Eu me lembro que, pelo menos até 81, 82, não se podia programar músicas de Vandré, Chico e Vinicius.

Ainda sobre a questão, Marlene Blois (s/d), também em entrevista aos "Amigos Ouvintes" da SOARMEC, afirma que a censura era constante: "Havia os 'censores', aqui dentro, lendo todos os roteiros. E eu acho que era até nessa sala onde nós estamos agora (a sala 201), que os infelizes liam, principalmente, os roteiros das aulas de história, de Educação Moral e Cívica [...]"17. Em uma entrevista cedida a um dos autores deste artigo, ao ser indagada sobre sua experiência com a censura no interior no Projeto, Blois (2015) relembra que a equipe do Projeto tinha que se adaptar ao que o censor desejava:

E às vezes eles empacavam com umas besteiras. Eu não falava nada. Ok tem
que tirar isso? Não pode? Assim que eu falava para eles. Não pode isso aqui?
Por que não pode? Está bem, não pode, então vamos tirar. Tira e regrava o pro-
grama. Tira esse pedaço. Às vezes não dava sentido, tinha que botar uma frase,
porque estava cortado (BLOIS, 2015 apud PINHEIRO, 2016, p. 87).

Falando sobre os radiopostos, Blois (2015) complementa que o material sonoro vinha previamente gravado e aprovado por Brasília, cujas retransmissoras deveriam respeitar, de maneira a limitar-se à reprodução. No que se referem aos conteúdos contidos nas apostilas, Blois (2015) afirma que eles seguiam as mesmas orientações das aulas radiofônicas, ou seja, também estavam sob o olhar da censura. As aulas transmitidas eram igualmente monitoradas, o que tornava quase impossível a infiltração de ideias comunistas, tal como sugere o já citado pedido de busca (608/71) ao posto do Projeto Minerva.

Perguntado a Blois (2015), quais as razões para tal desconfiança? Ela destaca que tal suspeita pode ter sido gerada pelo comportamento e/ou fala de algum membro que frequentasse o posto - a ponto de o próprio MEC ter-se manifestado pedindo investigação. Com base em sua experiência no período, ainda afirma que algum monitor - como em alguns casos faziam - poderia ter simplesmente desligado o rádio durante as aulas.

Aliás, pesquisa in loco no Arquivo Público do Paraná em Curitiba, o ofício 838/71 ${ }^{18}$ informa "que até esta data (16/12/1971), nada" encontrado. Entretanto, o Pedido de busca (608/71), já citado, não é único, pois, nos arquivos, existe uma variedade de pedidos de busca em escolas para investigação de professores e alunos suspeitos de subversão.

Sobre a questão, mais do que precisar se havia ou não infiltração comunista, é importa grifar que o Estado Civil-Militar não descuidou do controle político-ideológico. Nesse aspecto, por decreto e/ou pela reestruturação da legislação, a censura foi uma prática do governo. Segundo Garcia (2014), a Constituição de 1967 permitiu que o governo assumisse o controle nacional sobre as películas cinematográficas, peças teatrais, programas de rádio, de televisão, publicações periódicas e letras musicais. Nos pontos em que as leis constitu-

17 Entrevista disponível em: http://soarmec.com.br/marleneblois2.htm.

18 Ministério da Justiça (1971). Disponível em: https://www.documentosrevelados.com.br. 
cionais vigentes não davam amparo às medidas cerceadoras, os governos militares trataram de promulgar Decretos com base na Lei de Segurança Nacional. ${ }^{19}$

Ademais, a Escola Superior de Guerra (ESG) criada em 1949, para além de pensar o desenvolvimento econômico e social, busca formas para neutralizar ideias e ações que pudessem fomentar antagonismos na política. Pelo Decreto-Lei 898 de 1969, a ESG assume também um papel estratégico e "arma o Estado de meios legais para se opor a todas as manifestações e suas ameaças que visem à conquista subversiva do Poder" (ESG, 1975, p. 254 apud GONÇALVES, 2011, p. 5). Assim, a estrutura militar é reorganizada de modo que o Estado possa proteger o país, não somente dos inimigos externos, mas também das ideias consideradas contrárias aos ideais do Regime. Desta forma, cria-se um "mecanismo repressivo que possa, prontamente, desencadear a Ação-Resposta para garantir as instituições e manter o primado da lei e da ordem, o que se faz por meio da Defesa Interna" (ESG, 1975, p. 255 apud GONÇALVES, 2011, p. 5). No mesmo aspecto, houve outras estratégias, intituladas como "Operações Psicológicas":

2.1. Operações Psicológicas são aquelas que incluem as ações psicológicas e a guerra psicológica. Compreendem as ações políticas, militares, econômicas e psicossociais planejadas e conduzidas para criar em um grupo - inimigo, hostil, neutro ou amigo - emoções, atitudes ou comportamentos favoráveis à consecução dos Objetivos Nacionais.

2.2. A Ação Psicológica congrega um conjunto de recursos e técnicas para gerar emoções, atitudes, predisposições e comportamentos de indivíduos ou coletividades, favoráveis à obtenção de um resultado desejado.

2.3. Guerra Psicológica é o emprego planejado da propaganda e da exploração de outras ações, com o objetivo de influenciar opiniões, emoções, atitudes e comportamento de grupos adversos ou neutros, de modo a apoiar a consecução dos Objetivos Nacionais (ESG, 1975, p. 316 apud GONÇALVES, 2011, p. 6).

Assim, juntamente com a censura, foram criados mecanismos de propaganda dos valores nacionais e dos feitos militares, entre os quais, o ensino e o sistema de comunicação em massa (rádio, televisão e a imprensa) foram considerados privilegiados na sustentação ideológica dos militares no poder. Neste aspecto, na medida em que os generais buscaram conduzir o noticiário, trazendo à tona apenas as informações convenientes com seus interesses, focaram no discurso que havia um inimigo para ser combatido em nome da segurança nacional. Deste modo, não economizaram na produção e repetição do slogan: "Brasil grande potência", "este é um país que vai pra frente", "Brasil: ame-o ou deixe-o", "Quem não vive para servir ao Brasil, não serve para viver no Brasil", na mesma medida em que não se economizou na produção de aparatos censórios, inclusive da censura prévia ${ }^{20}$. Da mesma forma, o dinheiro público foi investido na promoção de eventos que pudessem

19 No Estado Civil-Militar foram promulgados vários Decretos. Referindo-se aos Decretos baseados na Segurança Nacional, Germano (1994, p. 64) destaca que houve uma mudança no conceito, pois, se na Constituição de 1946, referia-se à defesa dos inimigos externos e à preservação das fronteiras territoriais, na Constituição de 1967, em um período de Guerra Fria, atribui importância à defesa do "inimigo interno do Estado", ou seja, os ideais revolucionários que se inspiravam no "comunismo internacional".

20 A censura prévia foi regulamentada pelo Decreto-Lei 1077 de 1970, assim, toda matéria (jornalística e/ou cultural), antes de ser exposta ao público, deveria passar por uma revisão, podendo sofrer cortes. 
aproximar o exército da população, tais como: as paradas militares e o financiamento de esportes populares (GASPARI, 2002).

Entre os planos governamentais, a cúpula militar passou a investir no fortalecimento dos órgãos de censura e de repressão, entre os quais, o Serviço de Censura de Diversões Públicas (SCDP) e Divisão de Censura de Diversões Públicas (DCDP), aos cuidados do Ministério da Justiça (MJ), entravam em ação para controlar a informação e construir uma hegemonia política. Em conjunto, o Serviço Nacional de Informações (SNI) ${ }^{21}$, cujo primeiro organizador foi o general Golbery do Couto e Silva, assumiu o papel de supervisor e coordenador das atividades de informação, tanto no Brasil como no exterior, sendo um importante aparelho na repressão (SOARES, 1989).

De forma progressiva, para além de ações de convencimento, o governo ativa os aparelhos de coerção, entre os quais, a partir de 13 de dezembro 1968, com a publicação do Ato Institucional n. 5 (AI-5), alguns assumiram o papel de repressão aos supostos "transgressores". Segundo Gaspari (2002), o AI-5 foi o que mais impôs austeridade, na medida em que dissipou a ambiguidade anterior presente nos governos militares. Apoiando-se no livro A Revolução e o governo Costa e Silva, de autoria do general o General Jayme Portella de Mello, Gaspari (2002, p. 211) destaca que na "noite de 12 de dezembro de 1968", o general determinou que a Polícia Federal se "preparasse para calar as emissoras de rádio e televisão e enviar censores aos jornais do Rio e de São Paulo". Neste sentido, ainda descreve que os oficiais e delegados que foram até as redações, carregavam consigo "pequenos manuais", nos quais constava que o "objetivo da censura era 'obter da imprensa falada, escrita e televisiva o total respeito à Revolução de Março de 1964, que é irreversível e visa à democracia""'(GASPARI, 2002, p. 212).

Referindo-se especificamente ao manual da polícia carioca, afirma que nele constava que não poderiam ser divulgadas notícias que: "incitassem a luta de classes"; pudessem comprometer "a imagem ordeira e econômica do Brasil"; gerassem tumultos "comerciais, financeiros e de produção", sendo também proibido noticiar "atividades subversivas, greves ou movimentos operários" (Resistência, 21 de janeiro de 1969, p. 3 apud GASPARI, 2002, p. 212). ${ }^{22}$

Ainda neste contexto, por intermédio do Decreto-lei n. ${ }^{\circ} 66.862 / 1970$, segundo Muniz (2001, p. 184), a Polícia Militar ${ }^{23}$ passou a ficar responsável não apenas pelo "controle de multidões e as operações de choque nas situações de distúrbios civis", mas também pelas

${ }_{21}$ Subordinados ao SNI foram criados ou reestruturados os seguintes órgãos: Destacamento de Operações de Informações (DOI); Centro de Operações de Defesa Interna (CODI); Centro de Informações da Marinha (CENIMAR); Centro de Informações e Segurança da Aeronáutica (CISA); Centro de Informações do Exército (CIE); Operação Bandeirantes (OPAN) e o Departamento Estadual de Ordem Política e Social (DEOPS).

22 No que se refere à mídia, destaca-se que enquanto algumas redações e jornalistas foram silenciados pela censura e prisões, a mídia comerciária rendeu-se aos interesses de quem estava no poder. Assim, em seu papel de noticiar, aproximou-se dos valores do liberalismo e passou a narrar os fatos ao gosto de quem a controlava e a financiava, ou seja, o poder civil-militar. Sobre, consultar: Arbex Jr., (2001).

23 Muniz (2001, p. 183), em uma recuperação histórica da Polícia Militar, destaca que ela apareceu pela primeira vez na constituição de 1934, como "forças auxiliares" do exército. Na constituição de 1946, esta definição foi ampliada para "forças auxiliares e reservas do exército". As demais cartas constitucionais brasileiras (1967, 1969 e 1988) reproduziram esta definição. Em 1967, foi criada a Inspetoria Geral das Polícias Militares, subordinada ao exército que tinha atribuições reguladoras e fiscalizadoras. 
"atividades de "caça às bruxas"'. Desta forma, passou a "integrar o serviço de informações e contrainformações do Exército", constituindo-se como "policiamento ostensivo fardado", tornando-se "responsáveis pelo patrulhamento urbano convencional". Segundo Fico (2002), com a chamada "linha dura" 24 no poder, foram implantados "sistemas" que fariam a "Operação Limpeza". Assim,

criou a polícia política, instituiu um sistema nacional de 'segurança interna', reformulou e ampliou a espionagem, estabeleceu um procedimento de julgamento sumário para confiscar os bens de funcionários supostamente corruptos, implantou a censura sistemática da imprensa, instrumentou a censura de diversões públicas para coibir aspectos políticos do teatro, cinema e TV, dentre outras iniciativas [...] (FICO, 2002, p. 255).

$\mathrm{Na}$ ordem da Segurança Nacional, os atos de contestações contra o governo e/ou as divulgações de ideias supostamente transgressoras aos princípios político-ideológicos do Regime Civil-Militar, juntamente com as guerrilhas armadas, passaram a ser tratadas como crimes dignos de punição, ao mesmo tempo em que um aparato policial e investigativo foi montado para encontrar, prender e eliminar o que parecia destoar do Estado Civil-Militar. Neste propósito, segundo Gaspari (2002), a censura aliou-se também à tortura. Assim, inúmeros Inquéritos Policiais Militares (IPM) foram criados como forma de aplicar punições (prisões, cassações de mandatos e suspensões de direitos políticos), enquanto nos porões do Regime a tortura tornou-se uma prática. ${ }^{25}$

No que se refere à educação, a censura também foi ativa. Segundo Germano (1994), as universidades sofreram processos sistemáticos de intervenção. Muitos professores tiveram seus direitos políticos e profissionais suspensos e o movimento estudantil sofreu forte repressão, além de ser posto na ilegalidade.

Com a finalidade de impedir a divulgação de ideias que pudessem pôr em cheque o Regime, o Estado usou da censura política. Assim, impediu eventos públicos e publicação de jornais, livros e revistas. Porém, não se limitou à proibição de eventos públicos e/ou da divulgação de denúncias e críticas ao governo. A censura foi além, fechou redações, caçou mandatos políticos, retirou direitos profissionais, encarcerou e abriu inquéritos de investigação.

No seu processo de atuação, a censura política foi mais do que um código de restrição à conduta, ela foi o cerceamento do pensamento político. Neste aspecto, os governos militares buscaram impor sua forma de governar como única e correta. Uma visão que se alinhava aos pressupostos positivistas da ordem e progresso ${ }^{26}$. Por conseguinte, a censura política não foi apenas um produto, mas também foi produtora das relações sociais. Deste modo, ela também contribuiu para influenciar as análises e os julgamentos, os quais deram materialidade a muita imaginação política. Então, ao contrário dos que alguns pensam, os

24 Segundo Germano (1994), a "linha dura" governava por intermédio da repressão e punições, entretanto, os chamados "moderados" não apoiavam as punições e sentiam-se desconfortáveis perante o AI - 5 .

25 Sobre a prática da tortura, Gaspari (2002) relata que inúmeras denúncias chegaram à Conferência Nacional dos Bispos. Neste aspecto, destaca o papel da Igreja Católica, a qual na figura de D. Helder Câmara buscou combater tal prática denunciando-a ao mundo, porém, outra ala da Igreja, representada por D. Eugênio Sales, preferiu abafar as denúncias e se colocou contra os torturadores.

26 Sobre consultar Favoreto e Galter (2020). 
princípios da censura não se trataram da defesa da moral e dos bons costumes, mas se firmaram na imposição de uma visão política sobre os costumes e vivências sociais.

Neste sentido, destaca-se que os princípios censórios não existem por si mesmos, nem são estáticos, mas se fazem e se refazem permanentemente nas relações sociais. No que se refere à censura política, ela é influenciada de maneira mais imediata pelos participantes. Assim, insere o poder executivo em uma posição privilegiada, principalmente quando tem o domínio sobre os meios de comunicações e usa dos aparelhos repressivos para controlar a informação e a opinião. De tal modo, o discurso do Regime Militar também foi providencial, não apenas no sentido de justificar a tomada do poder, mas também por se apresentar como salvadores mediante a um suposto perigo, gerando muitos aparatos militares, imaginação e suspeitas.

Noutros termos, com base em Bakhtin (2004, p. 112-3. Grifos do autor), destaca-se que "O mundo interior e a reflexão de cada indivíduo têm um auditório social próprio bem estabelecido, em cuja atmosfera se constroem suas deduções interiores, suas motivações, apreciações, etc." Neste caso, a cúpula militar utilizou-se dos aparelhos do Estado, sejam os de propaganda, da educação e/ou da censura/repressão para criar uma atmosfera favorável para a manutenção da sua hegemonia política.

\section{CONSIDERAÇÕES FINAIS}

Esse artigo surgiu do interesse em compreender os fundamentos de um pedido de busca ao posto do Projeto Minerva que estava sob suspeita de haver a infiltração de ideias comunistas. Para tanto, procurou saber o que foi o Projeto Minerva em seu contexto histórico-social, atentando-se para o embate político e como ocorria a cesura no período.

Ao acompanharmos o processo histórico do Projeto Minerva, verificamos que sua história se constituiu no desenvolvimento tecnológico das comunicações, ao passo em que objetivou responder às demandas sociais e às necessidades produtivas criada com o chamado "milagre econômico". Também serviu de aparelho ideológico do Estado, assumindo o papel de divulgar a ideologia da ordem e do progresso. Igualmente, foi um importante difusor do Estado benéfico, principalmente para a população que estava fora dos bancos escolares. Portanto, o Projeto Minerva, em conjunto com as demais reformas educacionais e propagandas do governo, buscou legitimar e manter a hegemonia do poder militar.

Porém, se as reformas educacionais tinham entre os objetivos preparar a população para novas necessidades produtivas, legitimar e manter a hegemonia política do Regime, por outro, a educação pública se constituiu na medida do interesse do capital. No caso, buscou-se ampliar o número de vagas escolares e de pessoas preparadas para o mercado de trabalho, porém, com menor tempo e custo financeiro possível. Assim, o Projeto Minerva, realizado na forma de Educação a Distância, foi providencial. Deste modo, o governo forneceu a infraestrutura técnica e administrativa para seu funcionamento, mas economizou nas relações de ensino, principalmente, pagando baixíssimos salários e precárias contratações de trabalho aos monitores, dos quais também não se exigia qualificação. Contudo, eram os monitores que estavam em contato direto com o aluno e poderiam diminuir suas dificuldades, o que resultou em muitas improvisações e, consequentemente, em fracassos escolares. 
Se houve economia para o ensino, no que se refere à luta ideológica, o investimento foi amplo. No caso, houve um elevado investimento em propaganda e na patrulha ideológica, inclusive, criou-se um complexo aparato de investigação, censura e punição. Neste sentido, um relativo percentual do orçamento do Estado, o qual poderia ser investido na construção de escolas, em formação de professores e/ou na manutenção do quadro de funcionários, técnicos e professores, foi gasto em propaganda e em aparelhos de coerção contra os "subversivos".

No que se refere à suspeita mencionada, pelos relatos e observando o contexto, principalmente, atentando-se para o clima gerado com os discursos de Segurança Nacional e o AI-5, destaca-se que ela pode ter sido mais resultante da atmosfera política do que uma real infiltração de ideias comunistas e, neste sentido, buscou-se refletir sobre o significado social da censura.

A censura política no Regime Civil-Militar, apoiada na Lei de Segurança Nacional, não estabeleceu apenas restrições à liberdade de expressão, mas inserida em um contexto de propaganda e de valorização das forças armadas frente a um suposto inimigo, aguçou os sentidos e abriu o caminho dar materialidade à muita imaginação.

\section{REFERÊNCIAS}

ALVES, Maria Helena Moreira. Estado e oposição no Brasil (1964-1984). Petrópolis: Vozes, 1984.

ARBEX JR. José. Showrnalismo. A notícia como espetáculo. São Paulo: Casa Amarela, 2001.

AGGARWAL, DD. History and scope of Distance Education. New Dheli: Sarup \& Sons, 2007.

BAKHTIN, Mikhail (Volochinov). Marxismo e filosofia da linguagem. São Paulo: HUCITEC, 2004.

BLOIS, Marlene: depoimento [jun. 2015] Rio de Janeiro. Entrevistador: PINHEIRO, Giovani Gonçalves.

BLOIS, Marlene. Entrevista concedida aos "Amigos Ouvintes" da Sociedade dos Amigos da Rádio MEC (SOARMEC). s/d. Disponível em: http://soarmec.com.br/marleneblois2.htm Acesso em: 14 de dezembro de 2014.

BRASIL, Relatório do Grupo de Trabalho para a Reforma do Ensino de $1^{\circ}$ e $2^{\circ}$ Graus, instituído pelo Decreto $\mathrm{n}^{\circ}$. 66.600, de 20 de maio de 1970, Brasília, D.F, 14 ago.1970. Revista Brasileira de Estudos Pedagógicos, v.56, jul./set.1971, p.130-168.

CHASIN, J. A miséria da República dos Cruzados. Revista Ensaio, São Paulo, n. 15-16, p. 1-12, 1986. 
CUNHA, Luiz Antônio. Educação e Desenvolvimento Social no Brasil. Francisco Alves, RJ: 1978.

ESTADO DE SÃO PAULO. O Projeto Minerva inicia análise de seus problemas. Edição de 28 de janeiro de 1975, p. 26. Disponível em: http://acervo.estadao.com.br/pagina/\#!/ 19750128-30626-nac-0026-999-26-not. Acesso em 12 de abril de 2014.

FAVORETO, Aparecida; FIGUEIREDO, Ireni Marilene Zago; DEITOS, Roberto Antônio. Políticas educacionais para o Ensino Médio: a inclusão educacional/exclusão social como intenção e gesto. Revista Roteiro, Joaçaba, v. 44, n. 1, p. 1-24, jan./abr. 2019. Disponível em: https://core.ac.uk/download/pdf/235126098.pdf. Acesso em 11 de novembro de 2020.

FAVORETO, Aparecida \& GALTER, Maria Inalva. Teorias da transformação social: positivismo x marxismo, 2020. Revista Educere Et Educare, Vol. 15, N.34, jan./mar. 2020. Ahead of Print. DOI: 10.17648/educare.v15i34.23312 Disponível em: http://e-revista. unioeste.br/index.php/educereeteducare/article/view/23312/15674. Acesso em 18 de Janeiro de 2021.

FICO, Carlos. "Prezada Censura": cartas ao regime militar. Topoi, vol.3, no. 5. Rio de Janeiro, dezembro 2002, pp. 251-286 Disponível em: http://www.scielo.br/pdf/topoi/v3n5/ 2237-101X-topoi-3-05-00251.pdf. Acesso em 26 de março de 2017.

GARCIA, Miliandre, Quando a moral e a política se encontram: a centralização da censura de diversões públicas e a prática da censura política na transição dos anos 1960 para os 1970. Revista Dimensões, vol. 32, 2014, p. 79-110. Disponível em: http://www.periodicos.ufes.br/dimensoes/article/view/8319/5902. Acesso em 07 de abril de 2015.

GASPARI, Elio. A ditadura escancarada. São Paulo: Companhia das Letras, 2002.

GERMANO, José Willington. Estado Militar e educação no Brasil (1964 - 1985). São Paulo: Cortez, 1994.

GONÇALVES, Nádia G. Doutrina de Segurança Nacional e desenvolvimento na ditadura civil-militar: estratégias e a educação. Anais do XXVI Simpósio Nacional de História - ANPUH - São Paulo, julho 2011. Disponível em: http://www.snh2011.anpuh.org/ resources/anais/14/1300650153 ARQUIVO textoanpuh2011ngg.pdf. Acesso em: 18 de Janeiro de 2015.

GONZALEZ, Deborah. B.; SARAIVA, Karla. S. Educação nas Páginas da Revista Veja (1968-1978). In: $7^{\circ}$ Seminário Brasileiro de Estudos Culturais e Educação e $4^{\circ}$ Seminário Internacional de Estudos Culturais e Educação, 2017, Canoas. Anais do $7^{\circ}$ Seminário Brasileiro de Estudos Culturais e Educação / $4^{\circ}$ Seminário Internacional de Estudos Culturais e Educação, 2017. Disponível em: http://www.sbece.com.br/resources/anais/7/1495652940 ARQUIVO_EducacaonaRevistaVeja2.pdf. Acesso em: 03 de Outubro de 2017. 
IBGE. Censo Demográfico 1970-2000. Dados extraídos de: Estatísticas do século XX. Rio de Janeiro: IBGE, 2007. Disponível em: http://seriesestatisticas.ibge.gov.br/series.aspx?vcodigo=ECE305. Acesso em: 20 dez. 2017.

IPEA/IPLAN. Rádio Educativo no Brasil: um estudo. Brasília: Trabalho elaborado por equipe do Centro Nacional de RH do IPEA/IPLAN, 1976. 167p.

LUSTOSA, Rejânia Rebêlo. História e memória do Projeto Minerva em Teresina: a educação nas ondas do rádio (1971-1982). Teresina: Universidade Federal do Piauí. Dissertação de Mestrado, 2014. 93f. Disponível em: http://repositorio.ufpi.br/xmlui/bitstream/ handle/123456789/718/Disserta\%20Rejania\%202014\%20Mest.pdf?sequence=1. Acesso em 18 de outubro de 2017.

MINISTÉRIO DA JUSTIÇA - CENTRO DE INFORMAÇÕES DEPARTAMENTO DE POLÍCIA FEDERAL. Projeto Minerva de Educação, pedido de busca 608/71. 17 de novembro de 1971. Disponível em: https://www.documentosrevelados.com.br/repressao/ policia-federal-suspeita-de-possivel-infiltracao-de-comunistas-no-programa-da-radio-mec-projeto-minerva-da-educacao/. Acesso em 20 de março de 2014.

MUNIZ, Jaqueline. A Crise de Identidade das Polícias Militares Brasileiras: dilemas e paradoxos da formação educacional. Security and Defense Studies Review, Winter, v. 1, p. 177-198, 2001. Disponível em: https://s3.amazonaws.com/academia.edu.documents/46105655/Crise de Identidade da PM.pdf?AWSAccessKeyId=AKIAIWOWYY GZ2Y53UL3A\&Expires $=1552076226 \&$ Signature $=$ Ki\%2BWoPrxrFzdYv3tg898zZ9HS c4\%3D\&response-content-disposition $=$ inline $\% 3 \mathrm{~B} \% 20$ filename $\% 3 \mathrm{DA}$ Crise de Identidade_das_Policia_Milita.pdf. Acesso em 20 de dezembro de 2017.

PIMENTEL, Fábio Prado. O rádio educativo no Brasil - uma visão histórica. Rio de Janeiro. Editora Soarmec, 2004.

PINHEIRO, Giovani Gonçalves. Rádio educativo no contexto da ditadura militar. 2016. 103 f. Dissertação (Mestrado em Educação) - Universidade Estadual do Oeste do Paraná, Cascavel, 2016.

PINTO, Thiago Pedro; GARNICA, Antônio Vicente Marafioti. O Rádio e as Matemáticas: um estudo sobre o Projeto Minerva. Revista do Programa de Pós-Graduação em Educação Matemática da Universidade Federal de Mato Grosso do Sul (UFMS). Volume 7, número 13 - 2014. Disponível em < file:///C:/Users/SOFTWARE/Downloads/489-1200-1-PB\%20 (5).pdf. Acesso em 12 de abril de 2014.

ROCHA, Renato. Entrevista concedida aos "Amigos Ouvintes" da Sociedade dos Amigos da Rádio MEC (SOARMEC), s/d. Disponível em http://www.soarmec.com.br/renato.htm. Acesso em 23 de junho 2016. 
ROQUETTE-PINTO, Vera Regina. Roquette-Pinto, o rádio e o cinema educativos. REVISTA USP, São Paulo, n.56, p. 10-15, dezembro/fevereiro 2002-2003. Disponível em: http://www.usp.br/revistausp/56/02-veraregina.pdf. Acesso em 26 abr. 2014.

SOARES, Gláucio Ary Dilson. A censura durante o regime autoritário. Revista Brasileira de Ciências Sociais. Disponível: http://www.anpocs.com/images/stories/RBCS/10/ rbcs10 02.pdf. Acesso em 12 fev. 2021.

\section{DADOS DOS AUTORES}

\section{Giovani Gonçalves Pinheiro}

Mestre em Educação pela Universidade Estadual do Oeste do Paraná - UNIOESTE; Graduado em Comunicação Social pela UNIVEL. Membro do Grupo de Pesquisa História e Historiografia na Educação (Unioeste). Orcid: 0000-0002-7161-0813. giovanigpinheiro@ gmail.com.

\section{Aparecida Favoreto}

Doutora em Educação pela Universidade Federal do Paraná - UFPR; Mestre em Educação pela Universidade Estadual de Maringá - UEM; Graduada em História pela Universidade Estadual de Maringá - UEM. Docente Associada e Pesquisadora do Mestrado/Doutorado em Educação e do Colegiado de Pedagogia da Universidade Estadual do Oeste do Paraná, campus de Cascavel/PR. Membro e líder do Grupo de Pesquisa História e Historiografia na Educação (Unioeste). Orcid: http://orcid.org/0000-0003-3883-5604.

cidafavoreto20@gmail.com.

Submetido em: 08-03-2021

Aceito em: 08-08-2021 